\title{
GCU
}

Glasgow Caledonian

University

University for the Common Good

\section{Are students customers in higher education? Should we care about the answer?}

Campbell-Perry, S.; Williamson, E.

Published in:

INTED2017 Proceedings

DOI:

10.21125/inted.2017.0508

Publication date:

2017

Document Version

Author accepted manuscript

Link to publication in ResearchOnline

Citation for published version (Harvard):

Campbell-Perry, S \& Williamson, E 2017, Are students customers in higher education? Should we care about the answer? in INTED2017 Proceedings. IATED, pp. 1617-1623, 11th International Technology, Education and Development Conference, Valencia, Spain, 6/03/17. https://doi.org/10.21125/inted.2017.0508

\section{General rights}

Copyright and moral rights for the publications made accessible in the public portal are retained by the authors and/or other copyright owners and it is a condition of accessing publications that users recognise and abide by the legal requirements associated with these rights.

Take down policy

If you believe that this document breaches copyright please view our takedown policy at https://edshare.gcu.ac.uk/id/eprint/5179 for details of how to contact us. 


\title{
ARE STUDENTS CUSTOMERS IN HIGHER EDUCATION? SHOULD WE CARE ABOUT THE ANSWER?
}

\author{
Sonya Campbell-Perry ${ }^{1}$, Dr. Elizabeth Williamson ${ }^{2}$ \\ ${ }^{1}$ United Kingdom \\ ${ }^{2}$ United Kingdom
}

\begin{abstract}
The question surrounding whether students are indeed customers is both controversial and infinitely complex. The Higher Education sector continues to argue over this topic as it attempts to keep pace with a heightened consumerist market place (Saunders, 2014). As a result, this sector has become engaged in a discussion about how best to satisfy its students whilst delivering a high quality educational 'customer' experience whilst undergoing significant fiscal changes. A reduction in central funding in England has been largely offset by the ability to generate income through the introduction of 'top-up' fees. Whilst in Scotland, income continues to be reduced as this additional income source is not available.
\end{abstract}

As universities identify a need to deliver increased levels of student satisfaction, this understanding of the student as customer (SAC) may be interpreted differently across the institution, resulting in inconsistent approaches, as administrators, faculty, and students each have their own interpretation of their roles and contribution. The resulting debates over the provision of student services have caused friction between colleagues and as well as an inconsistent experience across the university for the students. Millward (2016) recognises this state of inconsistency of approach and its impact, within her research into formal student complaints and identifies an existent culture of defensiveness and protectionism across the UK HE sector, as HEls struggle to deal with students who actively feedback their dissatisfaction with their student experience. However there is a very real question that appears to be largely unanswered. Do students feel like customers? Finney \& Finney (2010) identified a gap in students' understanding of themselves as customers. This notion of SAC was found to have credence within Glasgow Caledonian University (GCU). The researcher interviewed 64 students whether they were customers of GCU. The responses indicated that over $70 \%$ felt in some way that they were customers of the university. These themes and their implications in terms of delivering a better student experience will be discussed in the presentation.

Whilst the debate may continue to rage over the status of students, there is an understanding that the increasingly competitive market place requires the student experience to be excellent, in order to increase future (paying) student numbers (Douglas et al., 2015). Therefore, HEls have been focused on the development of relevant service models which understand and support an excellent student experience delivered in a cost effective manner (Onsman, 2008). The use of 'Converged Service' models within the HE sector has been established within UK HEls since the 1980s and has had resurgence in interest in their use during the last decade (Melling \& Weaver, 2013).Evidence from recent research carried out, has shown that converged service model types have evolved and are also perceived to be effective at delivering high levels of student satisfaction in a resource efficient manner. In addition, 5 new models of converged service models have been recognised and these results will be disseminated within the presentation.

Keywords: student support, student experience, students as customers, service models, convergence. 


\section{Are students our customers in higher education? Should we care about the answer?}

\section{Introduction}

The Higher education sector is attempting to keep pace with a heightened consumerist market place (Saunders, 2014), where students now have the opportunity to access university places across the globe. Higher education (HE) has therefore become engaged in a discussion about how best to satisfy its students whilst delivering a high quality educational experience. The sector has also been confronted by significant fiscal changes including a reduction in central funding. This has been largely offset within UK universities (with the exception of Scotland), by the introduction of 'top-up' fees in September 2006. Reagan (2012) contends that the launch of top-up fees has supported a developing consumerist culture within the UK HE system.

A battleground has therefore emerged within the HE sector as the arguments surrounding whether the student can be seen as a customer is highly contested (Ness \& Osbourne, 2010). These debates have increased in volume, not just within HE as a sector, but internally within higher education institutions (HEls) themselves as disputes rage between colleagues from academia and professional support departments as to whether the students should be treated as a customer. There are a number of major criticisms levelled at the Student as Customer SAC model (Finney \& Finney, 2010) from the academic perspective within HE. One criticism is that the model subverts academic rigour, and that by pandering to student expectations grade leniency is promoted (Nguyen \& Rosetti, 2013). Following this leniency there is a reduction in the overall student responsibility for their own learning (Hassel \& Lourey, 2005), with an unrealistic expectation for what the university should deliver for the student.

A further argument to whether students should be treated as customers is offered, by Lomas (2007) who questions whether service delivery in $\mathrm{HE}$ is comparable to service provision in alternative sectors: 'The difficulty of regarding students as customers is based on the view that the professional service in higher education cannot be fully evaluated until some while after it has been provided. The student is only able to reflect fully upon the benefits of the knowledge and skills acquired and the attitudes that have been developed after a number of years when there has been sufficient opportunity to realize what they have learnt in a workplace setting' (Lomas, 2007,p.35). Therefore the continued use of SAC may have a propensity to distance the student from the process of learning itself. As a direct consequence, students acting as a customer will make increasing demands upon the university as their expectations and perceptions of what the university should deliver will need to be met, regardless of the longer term outcomes.

In addition, there are a number of outcomes which impact on the institution and academic practices and staff. Staff might find it more difficult to teach students using a short term approach, and in a subsequent lessening of their autonomy and authority, they will be forced to comply with students' demands as senior management require the delivery of student expectation and satisfaction 
(MacMillan \& Cheyney, 1996). In addition this understanding of the student as customer may be interpreted differently across the university, resulting in an inconsistent approach by administrators, faculty, and students, who will each have their own interpretation of their roles. This in itself places barriers between the collaboration and consistency of organizational relationships (MacMillan \& Cheyney, 1996; McCulloch, 2009).

Indeed recent comments by Baroness Wolf speaking in the House of Lords in relation to proposed educational reform, which will see (amongst other changes), the placing of student satisfaction at the heart of a new university ranking system, indicates just how emotive and conflictual the subject still remains within academia "The student satisfaction measure is fantastically dangerous. The way to make students happy is not asking them to do any work and giving them a high grade.. This will reduce standards and undermine quality. I just think this is totally mad, and destructive of everything universities stand for" (Baroness Wolf, The Telegraph: Accessed on the $8^{\text {th }}$ January, 2017).

\section{Why does student satisfaction matter to higher education?}

Millward (2016) within her research into formal student complaints within the UK HE Sector recognises that a state of conflict exists and comments that it has led to inconsistency of service provision within HEls. She identifies an existent culture of defensiveness and protectionism across the UK HE sector, as HEls struggle to deal with students who actively feedback their dissatisfaction with their student experience. This has resulted in a position whereby students become frustrated with the lack of response to their complaints, or in some cases the negative response which follows from their feedback about their student experience. Where the resulting response to the original complaint is poor, then 'double deviation' may occur. This is a situation whereby the organisations attempt to resolve the original service issue is equally as flawed as the original experience (Joireman et al., 2013).

This inability to treat students' views as important fails to recognise the necessity for student engagement within their own experience. As a result this belief manages to deconstruct the need for student responsibility and autonomy within their own student experience, thus in practice students do not have a voice or a significant role in their own experience. This is an ironic twist to the argument as by not regarding students as customers, and by not treating the student's feedback as important, this elicits a similar outcome from the criticism levelled at the SAC model, which is it decreases student autonomy for their own learning. Whether this student belief that they are customers is as a direct reaction towards the consumerisation of $\mathrm{HE}$ since the inception of top up fees ${ }_{2}$ the evidence remains uncertain. What is certain is that increasingly upset and unhappy students are willing and able to voice their concerns in public forums, affecting league table results and potentially impacting on the HEls ability to attract new students to their courses (Douglas et al., 2015). 
Whilst the current position in Scotland differs from that of the rest of the UK, where domestic (resident in Scotland) students have their fees paid direct to the university by the Scottish government, nondomestic, that is other UK students and international students are still expected to pay for the cost of their course. It is anticipated that these fee paying students will hold higher expectations of what the university will offer them in relation to their satisfaction with their student experience. A study by Ibrahim et al. (2013) in to the perception of overseas students towards service quality in Scottish HEls agrees with this assessment as it identified a service gap in the delivery of the student experience as being '..the lack of prompt responses given by staff to students..' and that HEls should '..therefore deploy their staff in an efficient manner, for which good service can be delivered' (Ibrahim et al., 2013, p.28).

This notion of students-as-customers was found to have credence within Glasgow Caledonian University (GCU), despite a vast difference in the funding structure for Scottish students in relation to their English and American counterparts as previously outlined. A small scale research project by the author asked students about their perception of being a customer within GCU (Campbell- Perry, 2014). The researcher interviewed 64 students across the three faculties of Business, Health and Engineering during 2014, and asked specifically whether they were customers of GCU. The responses indicated that over $70 \%$ felt in some way that they were customers of the university. This was particularly interesting when reviewing the statements of Scottish undergraduate (UG) students.

Table.1. Why do GCU students see themselves as customers?

\begin{tabular}{|l|l|l|}
\hline Themes & Summary code & Frequency \\
\hline Service provision & SER & 15 \\
\hline Paying for it (education) & PAY & 12 \\
\hline Consumer/consuming/using & CON & 12 \\
\hline Outcomes/product & OUT & 8 \\
\hline Choice & CHO & 6 \\
\hline Advice/Help/complain & ADV & 4 \\
\hline
\end{tabular}


There were three key themes that appeared to favour an understanding of their customer status:

(1) The university provides a service that they use

(2) Education is paid for (although not necessarily by themselves).

(3) They were consuming a service.

There was a strong notion that receiving a service, paying for that service, and indeed consuming that service were strong indicators of customer -like status:

'...the Scottish government have paid my tuition fees....when you paid for something you usually want to see an outcome or product.l'm that product..they're gonna want to see the best product to come out...'(Scottish, UG)

¿I am a paying student...so I'm definitely a customer...as I'm consuming the education...' (Scottish, UG)

'...we come to classes and we use all the services..we get a degree at the end, like we have the product at the end...' (Scottish, UG).

This was in direct contrast to the assumption that as Scottish UG students didn't pay fees their perception would not be strongly in favour of a customer status. Those that did not see themselves as customers were less sure of what their relationship could be perceived as, but offered alternative suggestions such as 'working with' the university, being part of a team, part of the family or member of the university.

I don't see myself as a customer...l really see myself more as a member...helping enable the university..kinda improve the university' (Male post-graduate (PG) student).

The emergent themes from GCU study are echoed by Saunders belief that the exchange of money for educational services makes customer centricity a priority for HE (Saunders, 2014). This notion is also advocated by Mark (2014) in his review of student satisfaction and customer focus in higher education in Canada. He states that it must now be acknowledged by the HE sector '..that students, by paying for the guided learning experience, and by being selective about the institutions and career paths they choose, and by specifying many aspects of their educational experience-do very much comport themselves as customers, and merely stating emphatically that they do not does little to alter the nature of their behaviour' (Mark, 2014, p.9). This is clearly seen by a sample of statements from the transcribed interviews of 12 of the GCU students who stated that they held a customer status due to the need to pay for their university experience, or a further 12 who stated they consumed 'educational services'. Further evidence to support this notion is found in the published literature where it is argued that HE may need to accept that students can perceive themselves to be on some, if not all levels a consumer within their university experience (Saunders, 2014). Saunders (2014) suggests that students do not necessarily need to see themselves as customers '..to embrace a customer orientation, as their beliefs and behaviours often demonstrate the extent to which they adopt a customer orientation' (Saunders, 2014, p. 204). This, he explains has led to a situation whereby the 
notion of students as customer is not made explicit by the university, but as a direct result promulgates a culture of customer orientation, where there is a campus wide focus on student satisfaction.

So in essence UK universities, including Scottish Universities, have to provide higher levels of service to deliver student expectations. This is at a time where institutional resources are being stretched in the face of decreasing central funding levels (Bulpitt,2012). McCaffery (2010) argues that one of the major challenges that now face higher education institutions (HEIs) lies in transitioning into a role where they have to '..do 'more' (that is teach more students) with 'less' (fewer resources) while simultaneously maintaining 'quality' (McCaffery, 2010,p.1).

In order to maintain their league table rankings over the longer term, institutions are consequently tasked with managing the internal ramifications of these funding changes at a time where there are increasing numbers of demanding students. Watson and Amoah (2007) suggest that the impact of attempting to balance the internal driver of resource efficiency, and the external driver of student satisfaction, have resulted in staff alienation, cynicism with change, demoralisation and disengagement. Indeed surveys carried out with HE staff over the last decade by The Times Higher and on behalf of the University and Colleges Union (UCU) have indicated that unreasonable workloads, working longer hours, combined with unrealistic expectations from senior management has led to increasing instances of stress and bullying being experienced by academics within HEls (The Times Higher Education, 2016).The challenge facing the HE sector is indeed a formidable one, balancing the needs and expectations of increasingly expectant students, with decreasing resources.

\section{So how does HE support the student experience?}

There is a very real question that appears to go largely unanswered within the sector. Do students actually feel like customers? And if so what impact does that have on how, when and what universities are required to do to support their students? Finney \& Finney (2010) in their research on student understanding of SAC identified this gap in understanding of whether US students perceived themselves to be customers. The gap, they stated, was being created as institutions increasingly implemented a SAC model without identifying the impact of its use, and without ascertaining how closely their students identified themselves as customers, and if this was indeed the case, how strongly and in what situations did they subscribe to these beliefs. The findings of their study did strengthen the notion that US students felt themselves to be customers, involved in an 'exchange' with the university. Therefore it was suggested that universities needed to focus on defining and highlighting the student responsibilities within their own student experience, to better inform their student 'customers' that they had a significant part to play in achieving a satisfactory student experience as they must '..co-produce their desired educational outcomes. Universities could emphasise student's accountabilities for helping create knowledge and for meeting learning expectations' (Finney \& Finney, 2010, p.287).

Tomlinson (2016) undertakes a review of the 'student consumer' in UK higher education. The research identifies a wide variation of student attitudes toward holding a consumerist approach to their 
educational experience. However, it was understood that despite a variation within the views that students held toward being a consumer, there was emerging student identification with a consumerist approach. As a consequence students felt that they were in a position of increased bargaining power with the organization in relation to the delivery of their own learning. What appeared very interesting was that in tandem with this power shift, a balance was created as students felt increasingly responsible for their own part within the process. Universities need to harness this student responsibility by describing and clarifying what students are expected to do and when.

Tomlinson (2016) goes on to state that a widely applied metaphor that captured students perception of their educational experience was one of 'investment', and that as a direct result student expectations of their teaching and learning were 'clearly rising' in to the value they were deriving from their investment. However he posts a note of caution for institutions that the variation of student views and beliefs toward a consumerist approach not only differs between student, but is also changed by "..specific context and student experience at different points in times" (Tomlinson, 2016, p.13). A more personalized approach is therefore required, one which delivers the right support and solutions to the individual student. Again universities are tasked with the problem of delivering personalized and satisfactory service, but in an efficient manner.

\section{Practical solutions}

Whilst the debate may continue to rage over what students are labelled as, there is an understanding that in the increasingly competitive market place that is now the international higher education sector, universities are required to deliver an excellent student experience. This not only satisfies their current students, but also ensures that as satisfied students leave their institution, they are happy to recommend their experience to others, and as a direct result their reputation grows which increases future (paying) student numbers applying to study at the institution (Douglas et al., 2015; Ibrahim et.al., 2013). With these external factors in mind HEls have been focused on the development of relevant service models which understand and support an excellent student experience, whilst ensuring these services are delivered in a cost effective manner (Onsman, 2008).

The implementation of 'Converged Service' models within the HE sector has been well established within UK HEls for over three decades (Appleton, 2012). However these models of service delivery have once again been under review following the resurgence of interest in their use during the last 10 years (Melling \& Weaver, 2013). Converged service was originally defined within the HE sector as 'The bringing together of the library and the computer service, possibly with other separate support services, under the management of an executive director..' (Pugh, 1997, p.3). As such the provision of converged service models had largely been thought to require the integration of the 'Information Services' departments, commonly library and IT services, which had been driven by the technological advancements that finally brought computing to mainstream usage within the sector during the 1990s (Royan, 1994). Pugh (1997) conducted the last UK wide review of convergence where it was identified 
that all the convergence models reported at that time featured library and IT services. It was also noted that less than $20 \%$ of the converged models integrated one or more of the student support departments (such as careers or student welfare) into the model with Library and IT.

Whilst two decades have now passed since Pugh's (1997) original work into convergence, it appears that converged service models are still evident in their practical application within the UK HE sector. The research set out to identify whether anything had changed during this time period, and paid particular attention to identifying what was meant by the term 'convergence', what was driving convergence, and what were the likely outcomes of convergence. By determining these factors it would allow for an appreciation of how effective converged models were at delivering their anticipated objects, one of which, it was assumed, would be to increase student satisfaction.

Bulpitt (2012) researched the use of 'super-converged' services within UK HEls. This is where HEls integrate all, or as many of their front facing student departments as is relevant, generally into one physical area. This 'bigger is better' model was being increasingly not only to satisfy increasing student expectation, who as customers were now demanding value, but also to counteract the fiscal implications of HE funding changes which has largely been driven by governmental policy. Consequently HEls were required to deliver higher levels of student satisfaction, but in a more efficient manner to meet these new budgetary restrictions. As identified previously these two main drivers for change in the sector were seen as potentially self-defeating as; 'These developments place services to students in the front line confronting universities..Because student services depend on staffing levels and require substantial accommodation for study, available for long hours, they are expensive to operate' (Bulpitt, 2012, p.4). The challenge therefore is to provide high quality services that increased student satisfaction, but were also delivered in a cost effective manner.

The recent research into converged service models in UK HEIS delivered 69 responses to a possible $159 \mathrm{HEls}$ ( $43 \%$ response rate). From the $25 \mathrm{HEls}$ that indicated they were using converged service models, 13 indicated that by 2016 increasing student satisfaction was the main driver, 13 cited it was to increase efficiency, and 2 stated specifically that were asked to reduce costs using the model. It appears that student satisfaction and resource efficiency were still the main drivers for convergence.

Table 2. Main drivers for convergence.

\begin{tabular}{lcc} 
Response & \multicolumn{2}{c}{ Count } \\
\hline To provide a better student experience & $\mathbf{1 3}$ & 39.496 \\
\hline To reduce duplicated effort and increase efficiency & $\mathbf{1 3}$ & 39.496 \\
\hline To reduce operational costs & 2 & 6.196 \\
\hline Other driver (please list) & 5 & 15.296 \\
\hline
\end{tabular}

Total: 33

Source: (Author: 2016). 
During follow up interviews with eight UK HEls a phenomenographic methodology was employed to ascertain the variation in experience of convergence. Whilst the interviews identified that whilst the main drivers could be simplified to delivering resource efficiency and increasing student satisfaction, there was a large variation in what was meant by these objectives to each individual institution. There were five categories of meaning found which applied to resource efficiency. On one side of the spectrum this meant cutting costs, on the other side, spending money to improve resource efficiency. The delivery of student satisfaction was found to have six different categories of meaning, from providing consistency of service to spending additional resource to specifically improve services.

The research found that convergence was no longer centred on the integration of Library and IT services, indeed one third of the HEls that responded had de-converged their IT and library converged models. However it appeared that in the intervening years HEls had started to implement converged models that integrated all of their Student Support services, without the presence of either library or IT. And whilst the tInformation Service Model was still represented, it appeared that the more favoured model or indeed models might include separating these services into at least two types of converged model. Of the eight insitutions interviewed (three of which had stated they were unconverged) seven had implemented standalone Student Services converged models.

Following this research the definition of convergence was reviewed and a more up-to-date definition is offered:

The provision of converged services within higher education allows for any number of non-academic services to be brought together in order to deliver more accessible, consistent, and integrated services, whose ultimate aim is to bring the student experience together. These services are likely, but not exclusively, delivered from a singular physical and virtual point, which allows students (and other customers) increased and consistent access to problem resolution and general support in order to maximise their potential within their university experience.

Evidence from recent research into the UK HE sector has shown that converged service model types have evolved and are now more likely to include multiple different services that may, or may not combine Library and IT. They are also perceived to be $80 \%$ effective at delivering high levels of student satisfaction in a resource efficient manner. Interestingly HEls that were categorised as modern established as degree awarding after the 1960s) perceived convergence models to be $10 \%$ more effective than their traditional university counterparts. The research identified five new converged service models in operation and produced a Converged Service Model Framework to support practioners in the field identify the most appropriate models to satisfy individual institutional needs. Whatever the outcome of the debate surrounding students as customers, we, as educational providers cannot lose sight of the fact that it is our student's perceptions and expectations that count, not our own arguments over whether they should be treated as partners, or clients or learners. Our students have been feeding back to us in relation to their expectations and satisfaction of their experiences within our institutions, and in most respect we are being found wanting. World-class service organisations are generally effective at listening to their customers so that they can identify, 
understand and ultimately successfully manage their customer expectations (Johnston \& Clark, 2008), and in this respect HEls can no longer hide behind the 'are students customers' argument as a means to do nothing.

\section{References:}

Douglas, J.A., Douglas, A., McClelland, R.J., \& Davies, J. (2015) “Understanding student satisfaction and dissatisfaction: an interpretive study in the UK higher education context", Studies in Higher Education, Vol. 40, no.2, pp. 329-349.

Finney, T.G. \& Finney, R.Z. (2010) "Are students their universities' customers? An exploratory study", Education + Training, Vol.52, no.4, pp.276-291.

Ibrahim,E., Wang,L.W., \& Hassan,A.,(2013) "Expectations and Perceptions of Overseas Students towards Service Quality of Higher Education Institutions in Scotland", International Business Research, Vol.6, no.6, pp.20-30.

Johnston, R., Clark,G., \& Shulver, M. (2012) Service Operations Management. Improving Service Delivery, $4^{\text {th }}$ Ed., Pearson Education Limited.

Joireman, J.,Grégoire, Y., Devezer, B. \&Tripp., T.M. (2013) "When do customers offer firms a "second chance" following a double deviation? The impact of inferred firm motives on customer revenge and reconciliation." Journal of Retailing Vol. 89.no. 3, pp. 315-337.

McCaffery,P. (2010) The Higher Education Mangers Handbook, $2^{\text {nd }}$ Ed. Routledge.

McCulloch, A. (2009) "The student as co-producer: learning from public administration about the student-university relationship", Studies in Higher Education, Vol.34. no.2, pp. 171-183.

Melling, M. \& Weaver, M. (2013) Collaboration in Libraries and Learning Environments, Facet Publishing, London.

Millward, C.V. (2016)"Student complainants - vexatious or vulnerable?" Perspectives: Policy and Practice in Higher Education, Vol. 20, no.4, pp.1-6.

Nguyen, A. \& Rosetti,J. (2013) "Overcoming potential negative consequences of customer orientation in higher education: closing the ideological gap", Journal of Marketing for Higher Education, Vol.23, no.2, pp.155-174.

Reagan, J.A. (2012) "The role obligations of students and lecturers in Higher Education" Journal of Philosophy of Education, Vol.46, no.1.pp.14-24. 
Onsman, A., (2008) “Tempering universities' marketing rhetoric: strategic protection against litigation or an admission of failure?", Journal of Higher Education Policy and Management, Vol. 30, no.1, pp.77-85.

Pugh, L. (1997) Convergence in academic support services, British Library Research and Innovation Centre Report 54.

Tomlinson, M. (2015) "Student perceptions of themselves as 'consumer' of higher education", British Journal of Sociology in Education, pp.1-15

Turner, C. (2017) The Telegraph Education News, Available from:

http://www.telegraph.co.uk/news/2017/01/08/universities-warned-snowflake-student-

demands/?WT.mc id=tmg share em

Watson, D. \& Amoah, M., (2007) The Dearing Report: ten years on. Institute of Education, University of London.

\section{REFERENCES [Arial, 12-point, bold, left alignment]}

[1] Reference [Arial, 10-point, left alignment, upper and lower case]

[2] A. Einstein, "General theory of relativity," Annalen der Physik, vol. 49, no. 7, pp. 769-822, 1916. 